\title{
Production and characterization of amphihaploid hybrids between Nicotiana wuttkei Clarkson et Symon and $N$. tabacum $\mathbf{L}$
}

\author{
Dorota Laskowska $\cdot$ Apoloniusz Berbeć
}

Received: 8 May 2011/Accepted: 22 July 2011/Published online: 10 August 2011

(C) The Author(s) 2011. This article is published with open access at Springerlink.com

\begin{abstract}
Nicotiana wuttkei Clarkson and Symon discovered in the 1990s in Australia may be of potential interest to breeders as it carries resistance to Peronospora hyoscyami de Bary. The crossability between $N$. wuttkei $(2 n=4 x=32)$ and three N. tabacum $(2 n=4 x=48)$ cultivars ('Puławski 66', 'Wiślica' and 'TN 90') and the morphology and cytology of their amphihaploid hybrids ( $2 n=4 x=40)$ were studied. Seeds were produced only when $N$. wuttkei was used as the maternal parent, but under normal germination all seedlings died. Viable $\mathrm{F}_{1}$ hybrids of $N$. wuttkei $\times N$. tabacum cv. 'Puławski' and N. wuttkei $\times N$. tabacum cv. 'Wiślica' were obtained only by in vitro cotyledon culture. The amphihaploid plants were intermediate between the parents for most morphological traits. In $46.4 \%$ of the PMC's, only univalents were present. The remainder of the cells had 1-5 bivalents and 1-2 trivalents. In spite of a detectable frequency of monads $(2.6 \%)$, dyads $(2.6 \%)$ and triads $(4.5 \%)$, the hybrids were self and cross sterile.
\end{abstract}

D. Laskowska $(\square) \cdot$ A. Berbeć

Department of Plant Breeding and Biotechnology, Institute of Soil Science and Plant Cultivation-State

Research Institute, ul. Czartoryskich 8, 24-100 Puławy,

Poland

e-mail: dlaskowska@iung.pulawy.pl
Keywords Nicotiana tabacum L. · N. wuttkei Clarkson et Symon · Interspecific hybridization . Amphihaploid · Cytology

\section{Introduction}

The advances in genetic engineering have to some extent eclipsed the importance of wide hybridization as a tool for gene transfer from phylogenetically distant sources, but this method may still be an asset in cultivar development especially when the use of transgenic methods is to be avoided. Since the pioneering work by Holmes (1938) wide crosses and synthetic amphiploids have played an important role in introgresssions of desirable traits from related species into cultivated tobacco. A considerable part of that effort was directed towards resistance to blue mould caused by Peronospora hyoscyami de Bary (Peronospora tabacina Adam), a devastating leaf disease now spread all over the world but originally endemic to Australia. At least a few native wild Australian tobaccos have evolved resistance to the blue mold pathogen. Among them, Nicotiana debneyi (Clayton 1968), N. goodspeedii, N. velutina (Wark 1970), N. excelsior and N. exigua (Gillham et al. 1977) have been reported as sources of resistance in developing blue-mold resistant tobacco cultivars.

Another potential candidate for possible resistance transfer to cultivated tobacco is N. wuttkei, a relatively recently discovered wild tobacco (Clarkson 
and Symon 1991), and yet another Australian species resistant to Peronospora hyoscyami (Laskowska and Berbeć 2003). Its originally reported chromosome number of 28 was subsequently corrected to 32 (Laskowska and Berbeć 2003). It is probably a natural allopolyploid of polyphyletic origin, as are other species of the Australian section Suaveolentes (Chase et al. 2003) and, like them, is a distant relative of the cultivated allopolyploid $N$. tabacum $(2 n=$ $4 x=48)$.

Although blue mold resistant cultivars of tobacco are widely used all over the world, diversification of available sources of resistance may be a worthwhile effort. The blue mold pathogen is notorious for mutations and the ability to develop new races (Masiak 1982; Zipper et al. 2009) and, according to the recent molecular studies (Milla et al. 2005), all important resistant cultivars probably derive their resistance from a single source $(N$. debneyi) even if previously reported otherwise. The hybridization of $N$. wuttkei with $N$. tabacum may also be important for basic studies in plant biology, gaining increased understanding of phylogenetic relationships among species, and for investigating aspects of evolution of the genus Nicotiana.

The present study reports on the production, morphology, meiotic behaviour and fertility of the amphihaploid hybrids between $N$. wuttkei and N. tabacum.

\section{Materials and methods}

Plant materials

Nicotiana wuttkei Clarkson and Symon $(2 n=4 x=$ 32 ) and three diverse cultivars of $N$. tabacum L. $(2 n=4 x=48)$ : 'Puławski 66', 'Wiślica', and 'TN 90 ' were used in the interspecific hybridization. The $\mathrm{F}_{1}$ hybrids containing a haploid set of chromosomes from each parental species $(2 n=4 x=40)$ are called amphihaploids (Goodspeed 1954; Chaplin and Mann 1961).

\section{Hybrid production}

Reciprocal crosses were made in the greenhouse of the Institute of Soil Science and Plant Cultivation
State Research Institute, Puławy, Poland in 2000. The crossability of $N$. wuttkei with $N$. tabacum cultivars and that of their hybrids was determined based on the number of pollinated flowers, the number of seeds obtained and the percentage of germinating seeds. Seeds of the resulted $F_{1}$ generation were germinated in vitro. Seeds were sterilized with $10 \%$ hydrogen hyperoxide for $20 \mathrm{~min}$ and placed on the LS medium (Linsmaier and Skoog 1965). Cotyledons from germinated seeds were cut into 2-3 segments each and placed on the Lloyds medium (Lloyd 1975). Regenerated shoots were rooted on the LS medium supplemented with $0.2 \mathrm{mg} / \mathrm{l} \mathrm{IAA}$ and $0.2 \mathrm{mg} / \mathrm{l} \mathrm{NAA}$ and transferred to pots with soil. The viable $F_{1}$ amphihaploid hybrids were grown to maturity in a greenhouse in 2001 .

Cytological studies

Mitotic chromosome counts were performed on juvenile corollas of greenhouse-grown plants using the method of Burns (1964). Corolla fragments were pretreated for $5 \mathrm{~h}$ in a $0.44 \%$ solution of 8 -oxyquinoline with saturated maltose solution, added just before using $(0.05 \mathrm{ml}$ maltose per $3 \mathrm{ml}$ 8-oxyquinoline). The preatreated material was fixed in the Carnoy solution (ethanol, chloroform and acetic acid-6:3:1) and acetocarmine (1.5\%)—stained preparations were made. Chromosome numbers were determined for ten cells of each obtained plant.

For observations of meiotic configurations, the flower buds at the appropriate stage (determined by a preliminary microscopic examination of one of the five anthers in a bud) were fixed in the Carnoy's fluid for $24 \mathrm{~h}$ and stored in $70 \%$ ethanol. Anthers were squashed in a drop of $1.5 \%$ acetocarmine. The meiosis tests included observations of chromosome pairing at metaphase I, meiotic irregularities at further stages (chromatin bridges, laggards) and number of microspores and micronuclei produced at the tetrad phase. On the basis of chromosome pairing data, the means and ranges for the numbers of bivalents, univalents and trivalents were estimated. Observations of meiotic configurations were performed in approximately 100 pollen mother cells (PMCs) prepared from anthers taken from four plants of each genotype.

Pollen viability was assessed with acetocarmine in at least 1,000 pollen grains from each plant. 


\section{Results}

\section{Crossability}

From $307 \mathrm{~N}$. tabacum flowers pollinated with $N$. wuttkei pollen, not a single seed capsule developed. Hybrid seeds were obtained only when $N$. wuttkei was used as the maternal parent. Their germination capacity was quite high and amounted to $66.9,80.0$ and $67.2 \%$ in crosses with $N$. tabacum cv. 'Puławski', 'Wiślica', and 'TN 90', respectively. Already at the cotyledon stage hybrid seedlings exhibited lethal symptoms, such as browning of the hypocotyl and of the roots, and all died when grown directly in the soil. When grown in vitro, nearly 99 percent of the seedlings also failed to survive beyond the cotyledon stage and only 11 of the 310 germinated hybrid seeds $(3.55 \%)$ produced viable hybrids from the $N$. wuttkei $\times N$. tabacum cv. Puławski combination; in the $N$. wuttkei $\times N$. tabacum cv. Wiślica combination, of the 2,333 seeds only 27 (1.16\%) produced viable hybrids (Table 1), for the total of 38 $\mathrm{F}_{1}$ hybrids. These plants had good vigour after transplanting into soil and developed to flowering.

Morphology and cytology of amphihaploid hybrids

Twenty-six plants resulting from the $N$. wuttkei $\times$ $N$. tabacum cross and regenerated from in vitrocultured cotyledons had 40 chromosomes in their somatic cells. The remaining 12 plants had double the number of chromosomes (80). There plants will be described in a separate report.

Morphologically, the 40-chromosome plants were intermediate between their parents (Fig. 1a, b, c).
Unlike in $N$. wuttkei, lower leaves did not form a basal rosette (Fig. 1b). The hybrids were as tall as or taller than the N. tabacum parent; the flowers were intermediate in shape and size (Fig. 1d) and pink in color, a trait of the N. tabacum parents used in this study. The leaves were more like those of the $N$. tabacum than those of $N$. wuttkei both in shape and in size (Fig. 1e).

The chromosome associations were observed in metaphase I of the $N$. wuttkei $\times N$. tabacum hybrids (Table 2), and some representative cells are shown in Fig. 2. Chromosome pairing varied from cell to cell, but there were no significant differences between the hybrids with regard to the calculated means of metaphase I associations per PMC. Meiosis was largely asynaptic. Of the 653 PMCs analyzed, 303 (46.4\%) had all 40 chromosomes as univalents. As it is usually the case with univalents, they failed to form a metaphase plate and were scattered throughout the volume of the PMC (Fig. 2a). The remainder of the cells had between 1 and 5 bivalents and 1-2 trivalents, and the rest were univalent. One (Fig. 2b), two (Fig. 2c, d), three, four (Fig. 2e) and five (Fig. 2f) bivalents were observed in 31.4, 14.1, 7.2, 0.6 and $0.2 \%$ of the PMCs, respectively. The modal number of bivalents was 0 . The great majority of bivalents observed in metaphase I were open, hence they had one chiasma each (Fig. 2b, c, d, e, f). Some chromosomes in bivalents appeared to be bound by very thin chromatin strands and tended to separate precociously (Fig. 2e). Trivalents (Fig. 2e) were recorded in a few PMCs.

Disjunctional abnormalities observed in later meiotic stages included chromatin bridges and lagging chromosomes, restitution nuclei and multipolar division spindles. The numbers of microspores at the tetrad stage are listed in Table 3 and in Fig. 3.
Table 1 Crossability between Nicotiana tabacum and $N$. wuttkei

a Obtained by in vitro cotyledon culture, calculated as (the number of viable hybrids/the number of hybrids used for cotyledon culture) $\times 100$

\begin{tabular}{|c|c|c|c|c|c|}
\hline \multirow[t]{2}{*}{ Cross } & \multicolumn{3}{|l|}{ Number of } & \multicolumn{2}{|l|}{ Percent of } \\
\hline & $\begin{array}{l}\text { Flowers } \\
\text { pollinated }\end{array}$ & $\begin{array}{l}\text { Seed capsules } \\
\text { obtained }\end{array}$ & $\begin{array}{l}\text { Seeds } \\
\text { obtained }\end{array}$ & $\begin{array}{l}\text { Seed } \\
\text { germinated }\end{array}$ & $\begin{array}{l}\text { Viable } \\
\text { hybrids }^{\text {a }}\end{array}$ \\
\hline $\begin{array}{l}N . \text { tabacum } \times N . \text { wuttkei } \\
N . \text { wuttkei } \times N . \text { tabacum }\end{array}$ & 307 & 0 & 0 & - & - \\
\hline N. wuttkei $\times$ Puławski 66 & 55 & 50 & 463 & 66.9 & 3.55 \\
\hline N. wuttkei $\times$ Wiślica & 50 & 30 & 2916 & 80.0 & 1.16 \\
\hline N. wuttkei $\times \mathrm{TN} 90$ & 75 & 55 & 2115 & 67.2 & 0 \\
\hline Total & 180 & 135 & 5494 & 72.6 & 0.95 \\
\hline
\end{tabular}



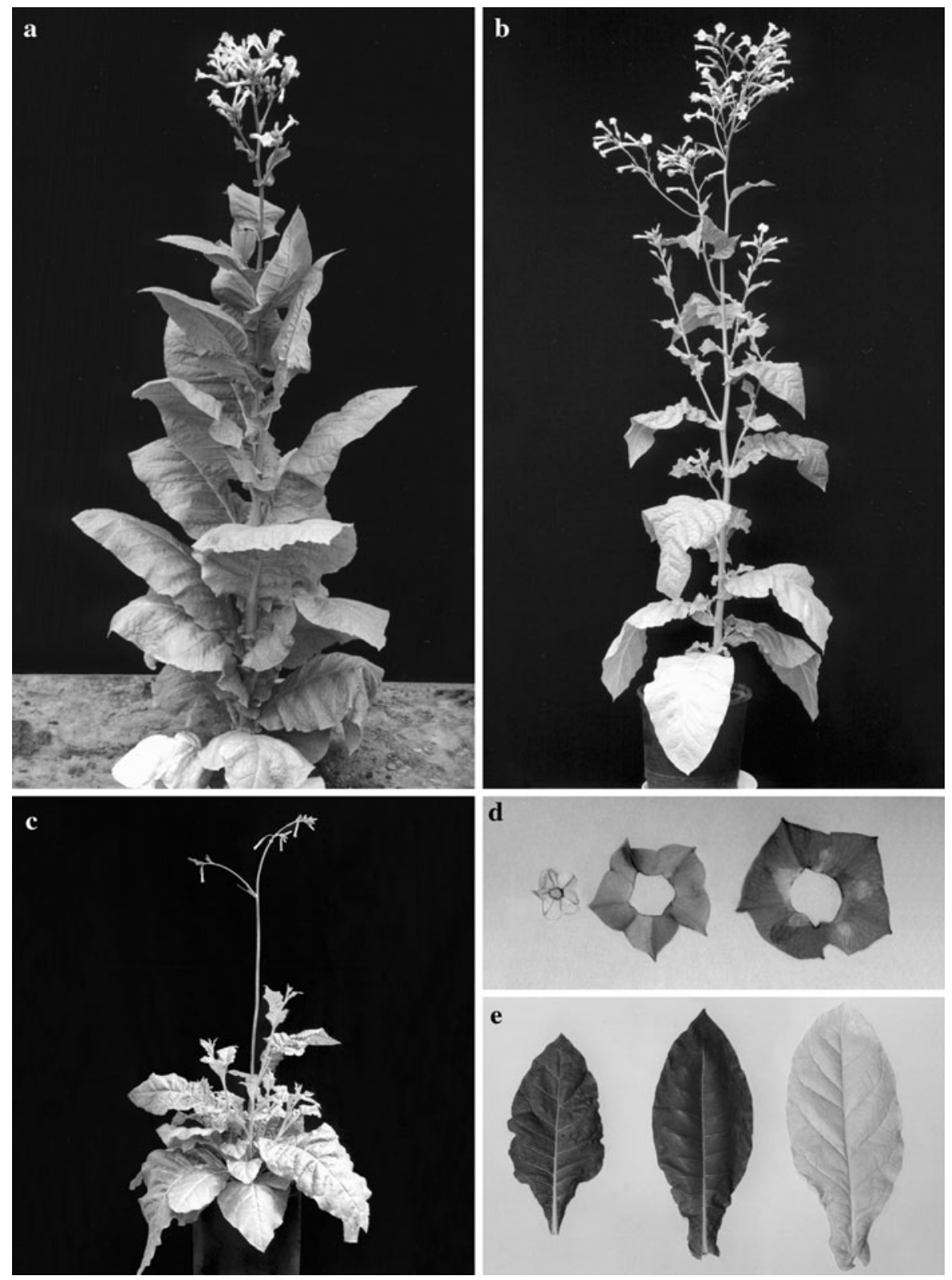

Fig. 1 Comparison of morphological attributes of $N$. tabacum cv. Wiślica, N. wuttkei and their $\mathrm{F}_{1}$ hybrid. Plant habit: N. tabacum cv. Wiślica (a), $\mathrm{F}_{1}$ hybrid (b), N. wuttkei (c), corollas (d) and leaves (e) of $N$. wuttkei, $\mathrm{F}_{1}$ hybrid and $N$. tabacum cv. Wiślica (left to right)

Tetrads were observed in the $82.3 \%$ of 468 PMCs examined (Fig. 3c) and monads (2.6\%), dyads $(3.8 \%)$, tryads $(4.5 \%)$ and pentads $(6.8 \%)$ in the remaining part of PMCs (Fig. 3a, b, f). Laggards not included in daughter nuclei formed micronuclei in $10.0 \%$ of all PMCs observed (Fig. 3d, e). The amphihaploid hybrids did not produce viable pollen and were self and cross sterile.

\section{Discussion}

Wide crosses have played an important role in the study of phylogenetic relationships among species and in widening the genetic basis of tobacco including the transferr of disease resistance traits to commercial $N$. tabacum cultivars. $N$. wuttkei is a newly discovered species (Clarkson and Symon 
Table 2 Metaphase I chromosome pairing in the amphihaploid hybrid Nicotiana wuttkei $\times$ N. tabacum

\begin{tabular}{|c|c|c|c|c|}
\hline \multirow[t]{2}{*}{ Hybrid } & \multirow{2}{*}{$\begin{array}{l}\text { Number of } \\
\text { PMCs observed }\end{array}$} & \multicolumn{3}{|c|}{ Chromosome pairing per PMCs } \\
\hline & & Univalents & Bivalents & Trivalents \\
\hline N. wuttkei $\times N$. tabacum cv. Puławski & 292 & $38.38 \pm 0.114^{\mathrm{a}}(29-40)^{\mathrm{b}}$ & $0.79 \pm 0.055(0-4)$ & $0.014 \pm 0.008(0-2)$ \\
\hline N. wuttkei $\times N$. tabacum cv. Wiślica & 361 & $38.21 \pm 0.106(30-40)$ & $0.89 \pm 0.052(0-5)$ & $0.003 \pm 0.003(0-1)$ \\
\hline Total & 653 & $38.26 \pm 0.078(29-40)$ & $0.84 \pm 0.038(0-5)$ & $0.008 \pm 0.004(0-2)$ \\
\hline
\end{tabular}

${ }^{a}$ Mean \pm SE

b Range

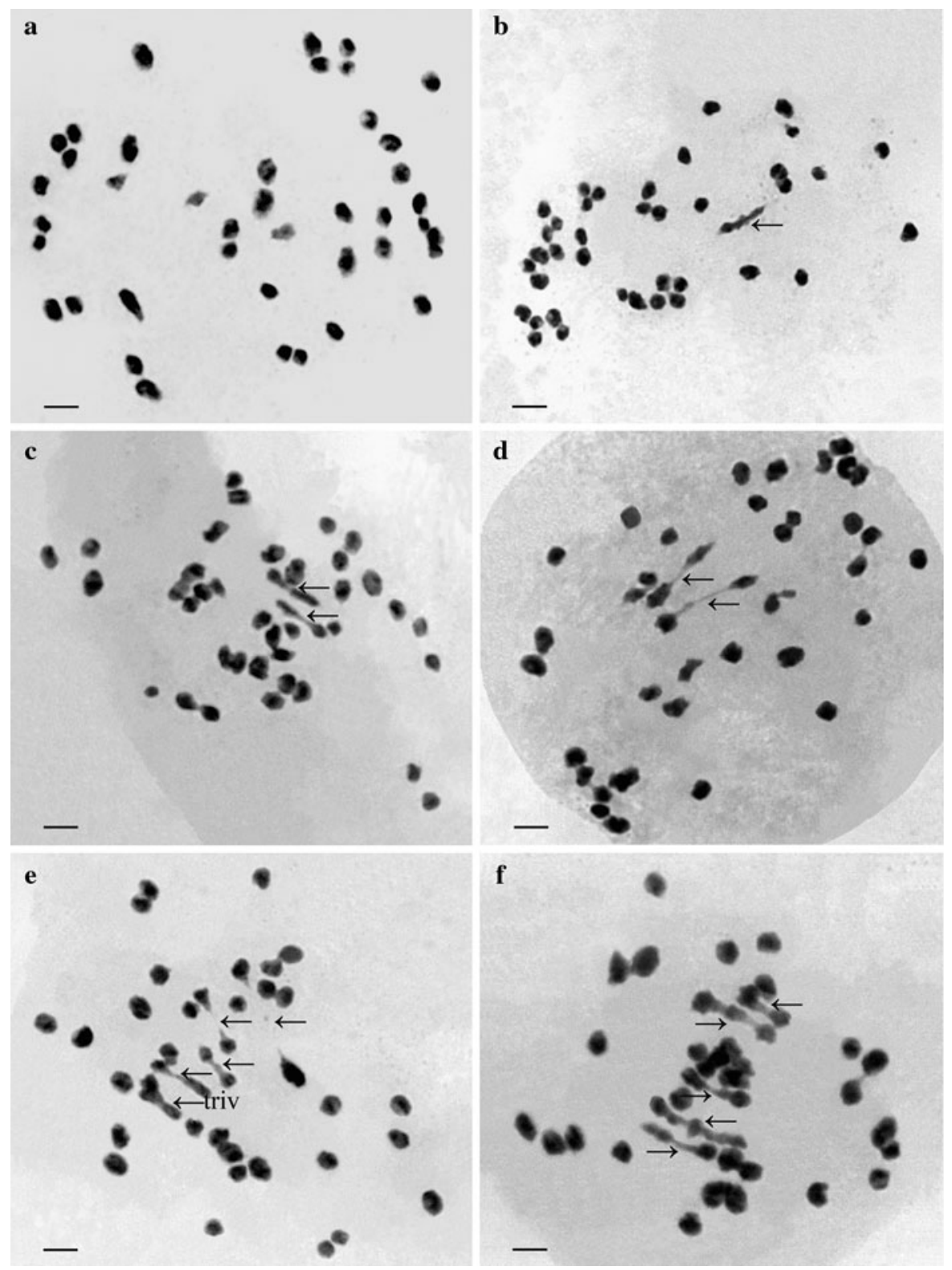

Fig. 2 Metaphase I in $\mathrm{F}_{1}$ hybrid $N$. wuttkei $\times N$. tabacum cv. Wiślica: a 40 I, b 1 II, 38 I c, d 2 II, 36 I, e 1 III, 4 II, 29 I-one of bivalents weakly conjugated f 5 II, 30 I. Bar: $5 \mu \mathrm{m}$; bivalents and trivalent marked by arrows 
Table 3 Microspores produced in $N$. wuttkei $\times N$. tabacum amphihaploid hybrid at the tetrad stage

\begin{tabular}{|c|c|c|c|c|c|c|c|}
\hline \multirow[t]{2}{*}{ Hybrids } & \multirow{2}{*}{$\begin{array}{l}\text { Number of } \\
\text { PMC's analyzed }\end{array}$} & \multicolumn{2}{|c|}{ PMC's observed $(\%)$} & \multirow[b]{2}{*}{ Tryads } & \multirow[b]{2}{*}{ Tetrads } & \multirow[b]{2}{*}{ Pentads } & \multirow[b]{2}{*}{ Micronuclei } \\
\hline & & Monads & Dyads & & & & \\
\hline N. wuttkei $\times N$. tabacum cv. Puławski & 260 & $5(1.9)$ & $10(3.8)$ & $15(5.8)$ & $211(81.2)$ & $19(7.3)$ & $29(11.2)$ \\
\hline N. wuttkei $\times N$. tabacum cv. Wiślica & 208 & $7(3.4)$ & $8(3.8)$ & $6(2.9)$ & $174(83.7)$ & $13(6.3)$ & $18(8.7)$ \\
\hline Total & 468 & $12(2.6)$ & $18(3.8)$ & $21(4.5)$ & $385(82.3)$ & $32(6.8)$ & $47(10.0)$ \\
\hline
\end{tabular}

Percentages of the total number in parentheses

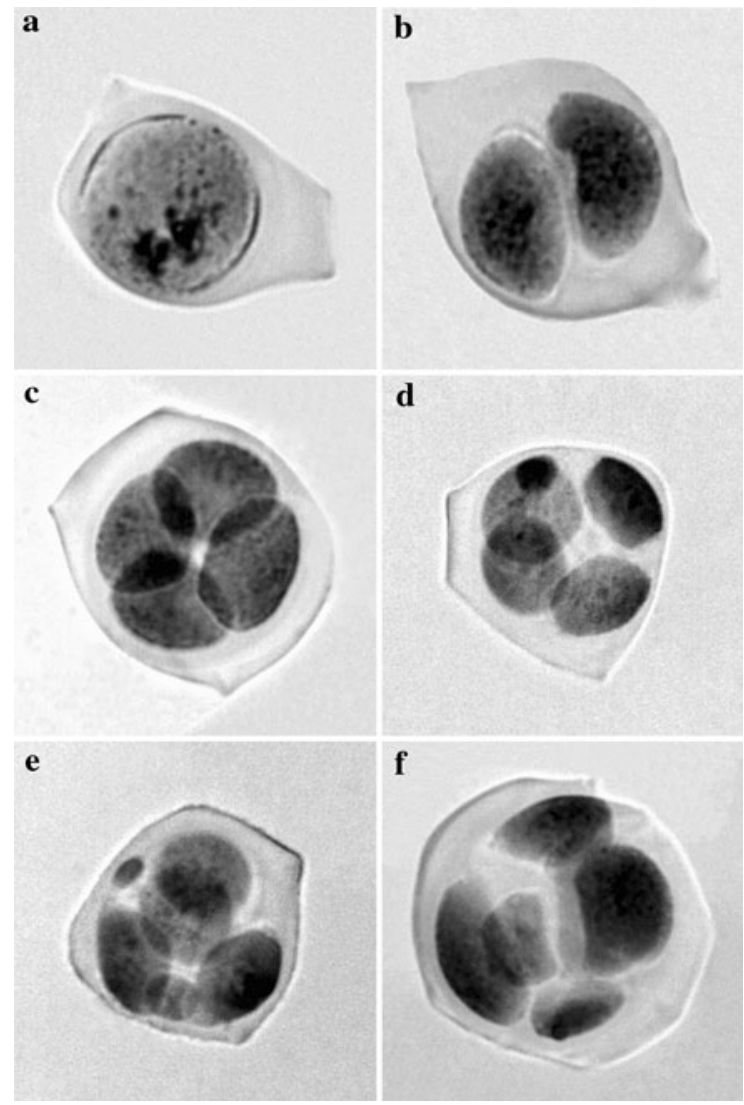

Fig. 3 Tetrad stage in $\mathrm{F}_{1} N$. wuttkei $\times N$. tabacum cv. Wiślica: a monad, $\mathbf{b}$ dyad, c normal tetrad, $\mathbf{d}$ tetrad with 1 micronuclei, e tetrad with 2 micronuclei, f pentad

1991) and as far as we know, no report on the use of this species in tobacco breeding has yet been published. Likewise, the amphihaploid hybrid $N$. wuttkei $\times N$. tabacum is a new combination of Nicotiana genomes, not reported heretofore.

Somatic chromosome numbers and their metaphase I pairing patterns clearly show that the 40-chromosome plants produced here were hybrids and amphihaploid, combining single haploid chromosome sets from each parent. These hybrids were produced only when $N$. wuttkei was used as the female parent. Such unilateral incompatibility frequently occurs in the conventional sexual interspecific crosses in Nicotiana, particularly when N. tabacum and a member of the section Suaveolentes are involved (Goodspeed 1954; De Verna et al.1987; Swaminathan and Murty 1957). The hybrids between $N$. wuttkei and three cultivars of $N$. tabacum used as male parents yielded filled capsules and the seeds germinated well, but nearly all seedlings died in the cotyledon stage. This is defined as "type II lethality" according to Yamada et al. (1999). Such phenomenon is frequent in the Nicotianas and is characteristic, among others, of reciprocal crosses between N. tabacum and many species from section Suaveolentes (Tezuka et al. 2010). In vitro culture allowed production of viable $N$. wuttkei $\times N$. tabacum hybrids, albeit with a low success rate. In several hybrid combinations in the genus Nicotiana, the problem of seedling mortality can be successfully overcome by an in vitro culture of cotyledons (Lloyd 1975; Doroszewska and Berbeć 1996; Ternovski et al. 1974). Gerstel et al. (1979) and Inoue et al. (1996) suggested that genetic factors are responsible for hybrid lethality. According to Marubashi and Onosato (2002) cotyledon culture applied at first by Lloyd (1975) to the hybrid $N$. suaveolens $\times$ $N$. tabacum might induce mutation in a gene or genes involved in lethality.

All viable amphihaploid plants in this study were phenotypically uniform and intermediate between the parent species for several morphological traits. This is typical for other hybrids of N. tabacum with the members of the section Suaveolentes (Kostoff 1943; Goodspeed 1954; Gerstel et al. 1979; De Verna et al. 1987). Some investigators dealing with interspecific 
Nicotiana hybrids reported departures from the amphihaploid chromosome number (Gerstel et al. 1979; Berbeć and Doroszewska 1981), and others recorded the expected number of somatic chromosomes (Doroszewska and Berbeć 1996; De Verna et al. 1987). Kostoff (1943) found that also unviable seedlings $N$. suaveolens $\times N$. tabacum had the expected number of 40 somatic chromosomes.

In the present study there was no appreciable effect of the genotype of $N$. tabacum (cv. Puławski vs. cv. Wiślica) on chromosome pairing in the $F_{1}$ hybrid. In some other studies (Doroszewska and Berbeć 1996; Williams and Pandey 1974), mean number of bivalents in the amphihaploids differed depending on the N. tabacum cultivar used as the male parent.

A number of bivalents ranging from 0 to 5 , with the modal number of 0 , places the hybrid $N$. wuttke $i$ $\times N$. tabacum in the "minimum" pairing category according to Goodspeed (1954). Such a low degree of pairing is in close agreement with the data of Kostoff (1943) for an analogical hybrid involving $N$. tabacum and $N$. suaveolens $(2 n=32)$ and this may be an additional justification for including $N$. wuttkei in the section Suaveolentes. Substantial variation for the bivalent number is a common phenomenon among $\mathrm{F}_{1}$ hybrids in Nicotiana. The reason is the formation of loosely paired associations (either true bivalents or not) by chromosomes with a low degree of homology (Goodspeed 1954; Takenaka 1962). Some of these associations are broken by premature disjunction. A low rate of associations of higher valencies in metaphase I as well as few chromatid bridges between the separating chromosomes in later meiotic stages may indicate a low rate of crossover events in these hybrids.

There is likelihood that at least some of the bivalents observed in the $N$. wuttkei $\times N$. tabacum amphihaploids, are autosyndetic (i.e. between the two subgenomes of $N$. wuttkei or $N$. tabacum) rather than allosyndetic (i.e. between the genomes of the parental species). This possibility is supported by findings by Collins and Sadasivaiah (1972) and by Takenaka and Tanaka (1956) who reported up to five bivalents in haploids of $N$. tabacum, clearlt a result of autosyndesis.

Fairly regular formation of tetrads in the hybrid $N$. wuttkei $\times N$. tabacum is in agreement with observations of Sficas (1963), who found a tendency toward an equal, rather than random, distribution of unpaired chromosomes to the poles in Nicotiana hybrids. A possible explanation for this is that some chromosomes tend to forming achiasmate associations and then move to opposite poles. Formation of restitution nuclei (dyads and monads) by $\mathrm{F}_{1}$ hybrids in Nicotiana is a regular phenomenon, apparently as a result of abnormal meiosis (Nikova and Zagorska 1990; Clayton 1950; Doroszewska and Berbec 1996). The hybrid $N$. wuttkei $\times N$. tabacum was no exception in this respect. However, the relatively high rate of unreduced gametes produced by that hybrid did not correlate with its ability to produce viable pollen. Absence of viable pollen in the $F_{1}$ hybrids of Nicotiana is a rule rather than an exception (Ternovski et al. 1974; De Verna et al. 1987) although hybrids of $N$. tabacum with other members of the section Suaveolentes did show some vestigial pollen fertility (Doroszewska and Berbeć 1996; Clayton 1950; Kostoff 1943). The failure of the restitution microspores (nuclei) in the $N$. wuttkei $\times N$. tabacum hybrids to develop into viable pollen could be a result of structural differences between the chromosomes resulting in gene imbalance. Other $F_{1}$ hybrids of $N$. tabacum with the members of the section Suaveolentes even if capable of producing partially fertile pollen were generally self- and cross-sterile (Kostoff 1943; Goodspeed 1954; Takenaka 1962; Wark 1970; Ternovski et al. 1974; De Verna et al. 1987; Doroszewska and Berbeć 1996).

In conclusion, sexual hybridization between $N$. wuttkei and $N$. tabacum is feasible although appears limited to a cross in one direction. As the success of transferring desirable traits from a wild into cultivated species largely depends on the pairing affinity of their chromosomes and thus on the potential for chromosome recombination, the opportunities for genetic exchange in this hybrid seem to be limited. Limited or otherwise, those opportunities can be explored only after restoring fertility to the hybrid since the directly produced amphihaploids of $N$. wuttkei $\times N$. tabacum were completely self and cross sterile.

Open Access This article is distributed under the terms of the Creative Commons Attribution Noncommercial License which permits any noncommercial use, distribution, and reproduction in any medium, provided the original author(s) and source are credited. 


\section{References}

Berbeć A, Doroszewska T (1981) Investigations of the interspecific hybrid Nicotiana amplexicaulis Burbidge $\times$ Nicotiana tabacum L. Genetica Polonica 22:197-207

Burns JA (1964) A technique for making preparations of mitotic chromosomes from Nicotiana flowers. Tob Sci 8: $1-2$

Chaplin JF, Mann TJ (1961) Interspecific hybridization, gene transfer and chromosome substitution in Nicotiana. N. Carolina State Coll Agr Exp Sta Tech Bul 145:1-31

Chase MW, Knapp S, Cox AV, Clarkson JJ, Butsko Y, Joseph J, Savolainen V, Parokonny AS (2003) Molecular systematics, gish and the origin of hybrid taxa in Nicotiana (Solanaceae). Ann Bot 92:107-127

Clarkson JR, Symon DE (1991) Nicotiana wuttkei (Solanaceae), a new species from north-eastern Queensland with an unusual chromosome number. Austrobaileya 3(3):389-392

Clayton EE (1950) Male sterile tobacco. J Hered 41:171-175

Clayton EE (1968) The transfer of blue mold resistance tobacco from Nicotiana debneyi. Part 4 . breeding progress 1957-1967. Tob Sci 12:112-124

Collins GB, Sadasivaiah RS (1972) Meiotic analysis of haploid and doubled haploid forms of Nicotiana otophora and N. tabacum. Chromosoma 38:387-404

De Verna JW, Myers JR, Collins GB (1987) Bypassing prefertilization barriers to hybridization in Nicotiana using in vitro pollination and fertilization. Theor Appl Genet 73: $665-671$

Doroszewska T, Berbeć A (1996) Chromosome pairing and microsporogenesis in interspecific $\mathrm{F}_{1}$ hybrids of Nicotiana africana with different cultivars of $N$. tabacum. J Genet and Breed 50:75-82

Gerstel DU, Burns JA, Burk LG (1979) Interspecific hybridization with an African tobacco Nicotiana africana Merxm. J Hered 70:342-344

Gillham FEM, Wark DC, Harrigan EKS (1977) Disease resistant flue-cured tobacco breeding lines for north Queensland I Resistance to blue mould, Peronospora tabacina. Aust J Exp Agricult Animal Husb 17(87):652-658

Goodspeed TH (1954) The genus Nicotiana. Chronica Botanica Co., Waltham, MA

Holmes FO (1938) Inheritance of resistance to tobacco-mosaic disease in tobacco. Phytopathology 28:553-561

Inoue E, Marubashi W, Niwa M (1996) Genomic factors controlling the lethality exhibited in the hybrid between Nicotiana suaveolens Lehm and N. tabacum L. Theor Appl Genet 93:341-347

Kostoff D (1943) Cytogenetics of the genus Nicotiana. State Printing House, Sofia

Laskowska D, Berbeć A (2003) Preliminary study of the newly discovered tobacco species Nicotiana wuttkei Clarkson et Symon. Genet Resour Crop Evol 50(8):835-839

Linsmaier EM, Skoog F (1965) Organic growth factor requirements of tobacco tissue cultures. Physiol Plant 18:100-127
Lloyd R (1975) Tissue culture as a means of circumventing lethality in an interspecific Nicotiana hybrid. Tob Sci 19:4-6

Marubashi W, Onosato K (2002) Q Chromosome controls the lethality of interspecific hybrids between Nicotiana tabacum and $N$ suaveolens. Breed Sci 52:137-142

Masiak D (1982) A study on the range of the host species to PT-2, a new strain of Perospora tabacina (Adam) (in Polish). Biuletyn Centralnego Laboratorium Przemysłu Tytoniowego 1-4:33-46

Milla SR, Levin JS, Lewis RS, Rufty RC (2005) RAPD and SCAR markers linked to an introgressed gene conditioning resistance to Peronospora tabacina D.B Adam. in tobacco. Crop Science 45(6):2346-2354

Nikova VM, Zagorska NA (1990) Overcoming hybrid incompatibility between Nicotiana africana Merxm and Nicotiana tabacum and development of cytoplasmically male sterile tobacco forms. Plant Cell Tiss Organ Cult 32:71-75

Sficas AG (1963) Statistical analysis of chromosome distribution to the poles in interspecific hybrids with variable chromosome pairing. Genet Res 4:266-275

Swaminathan MS, Murty BR (1957) One-way incompatibility in some species crosses in the genus Nicotiana. Indian $\mathrm{J}$ Genet Plant Breed 17:23-26

Takenaka Y (1962) Cytogenetic studies in the genus Nicotiana XVI. Reduction divisions in six interspecific hybrids between N. tabacum and other six species. Botanical Mag 75:237-241

Takenaka Y, Tanaka M (1956) Cytogenetic studies in the genus Nicotiana XIII. Haploid plant of Nicotiana tabacum. Botanical Mag 69:193-198

Ternovski MF, Butenko RG, Moisseva ME (1974) The use of tissue culture to overcome the barrier of incompatibility batween species and sterility of interspecies hybrids. Sov Genet 8:27-33

Tezuka T, Kuboyama T, Matsuda T, Marubashi W (2010) Seven of eight species in Nicotiana section Suaveolentes have common factors leading to hybrid lethality in crosses with Nicotiana tabacum. Ann Bot 106:267-276

Wark DC (1970) Development of flue-cured tobacco cultivars resistant to a common strain of blue mould. Tob Sci 14: 147-150

Williams E, Pandey KK (1974) Meiotic chromosome pairing in interspecific hybrids of Nicotiana II. South American species hybrids: the influence of genotype on pairing. $\mathrm{N} \mathrm{Z}$ J Bot 13:611-622

Yamada T, Marubashi W, Niwa M (1999) Detection of four lethality types in interspecific crosses among Nicotiana species through the use of three rescue methods for lethality. Breed Sci 49:203-210

Zipper R, Hammer TR, Spring O (2009) PCR-based monitoring of recent isolates of tobacco blue mold from Europe reveals the presence of two genetically distinct phenotypes differing in fungicide sensitivity. Eur J Plant Pathol 123:367-375 